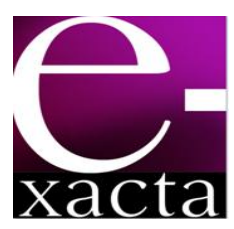

ISSN: 1984-3151

\title{
ANÁLISE DA DESTINAÇÃO DO ÓLEO DE COZINHA RESIDUAL NA REGIÃO OESTE DE BELO HORIZONTE/MINAS GERAIS E SUA TRANSFORMAÇÃO DE FORMA SUSTENTÁVEL
}

\author{
ANALYSIS OF THE APPLICATION OF RESIDUAL OIL COOKING IN WEST \\ REGION OF BELO HORIZONTE/MINAS GERAIS AND ITS \\ TRANSFORMATION SUSTAINABLY
}

Rogério Alexandre Alves de Melo'; Vitorio Delogo de Castro ${ }^{2}$

1 Doutor em Engenharia Química pela UFSCar-SP, 2000. Professor da Universidade Federal dos Vales do Jequitinhonha e Mucuri UFVJM. Diamantina, MG, BR. rogerio.melo@ict.ufvjm.edu.br.

2 Doutor em Química pela UFMG-MG, 2004. Professor do Centro Universitário de Belo Horizonte - UNIBH. Belo Horizonte, MG, BR. vitorio.castro@prof.unibh.br.

Recebido em: 16/09/2014 - Aprovado em: 20/10/2014 - Disponibilizado em: 30/11/2014

RESUMO: O presente estudo possibilitou uma análise de como é realizado o descarte inadequado do óleo de cozinha residual no entorno do Centro Universitário UNIBH-Campus Estoril, situado na cidade de Belo HorizonteMG, visando ao desenvolvimento de projetos de extensão e de pesquisa sustentáveis para a sua minimização e transformação final através de um sólido catalítico. O procedimento metodológico inicial envolveu o cadastramento dos síndicos dos condomínios no entorno do UNIBH com consequente aplicação de questionário, possibilitando como resultado uma análise do destino e danos causados pelo óleo de cozinha residual quando descartado de forma inadequada nessa região. Com o intuito de minimizar os impactos ambientais os discentes dos cursos de Engenharia Química e Ambiental do UNIBH, desenvolveram projetos de extensão, visando à produção de Biodiesel e de produtos de limpeza para doações para Instituições carentes da região do entorno do UNIBH e também participaram, por dois anos seguidos, do evento "dia da responsabilidade social", promovido pelo Núcleo Acadêmico do UNIBH. Em outra linha de estudo, houve o preparo de um material sólido catalítico do tipo MCM-41 para utilização em reações avançadas, como a hidrogenólise do glicerol, produzindo o componente 1,2propanodiol.

PalAVRAS-CHAVE: Óleo de Cozinha Residual. Sustentabilidade. Transformação. MCM-41.

ABSTRACT: This study allowed for an examination of how the improper disposal of waste cooking oil is held in the surroundings of the University Center Campus UNIBH Estoril, located in the city of Belo Horizonte-MG, aiming to develop outreach projects and research for sustainable minimization and ultimate transformation through a solid catalyst. The initial methodological procedure involved the registration of liquidators of condominiums surrounding the UNIBH with subsequent questionnaires, as a result enabling an analysis of the target and damages caused by the residual cooking oil when discarded improperly in this region. In order to minimize the environmental impacts of the courses the students of Chemical Engineering and Environmental UNIBH developed outreach projects, aiming at the production of Biodiesel and cleaners for donations to needy institutions in the region and around the UNIBH also attended by two consecutive years of the event "days of social responsibility," sponsored by the Academic Core UNIBH. In another line of study was the preparation of a solid catalytic material of the type MCM-41 for use in advanced reactions such as the hydrogenolysis of glycerol, 1,2-propanediol producing component.

KEYWORDS: Oil Residual Kitchen. Sustainability. Transformation. MCM-41.

\section{INTRODUÇÃo}

O óleo vegetal utilizado no preparo de alimentos compõe qualitativa e quantitativamente um dos maiores resíduos urbanos gerados no Brasil. Estimase que nacionalmente sejam produzidos quatro bilhões de litros/ano de óleo de cozinha residual. Ao 
considerar o potencial poluidor deste óleo e o seu descarte incorreto, além da falta de políticas públicas em relação a este assunto, o gerenciamento correto da destinação final deste resíduo a partir de um projeto de reciclagem torna-se uma alternativa sustentável na atualidade. Devido ao fato, discentes dos cursos de Engenharia Química e de Ambiental do UniBH - Centro Universitário de Belo Horizonte desenvolveram um esboço de um projeto para a reciclagem de óleo de cozinha residual domésticos, visando a minimizar o descarte inadequado. Os nomes desses discentes são listados ao final deste artigo, como forma de reconhecimento do trabalho desenvolvido por todos, em maior ou menor grau de participação, entre os anos de 2012 e inicio de 2014.

As atividades tiveram início com um levantamento sobre o descarte inadequado do óleo de cozinha residual no entorno do UniBH, no bairro Estoril, na cidade de Belo Horizonte-MG. Em seguida houve o recolhimento do óleo para estudo, produção de biodiesel e materiais de limpeza e para doação a instituições carentes, e ao final buscou-se um sólido catalítico para utilização em reação de hidrogenólise do glicerol produzido pela reação de transesterificação do óleo de cozinha coletado e tratado (CHEN; JAENICKE; CHUAH, 1997; MELO, 2000; MICHAEL, 2010).

A primeira tarefa do grupo foi a aplicação, pelos discentes, de um questionário junto aos síndicos dos condomínios do entorno do Campus Estoril do UniBH, localizado no bairro Buritis, e o cadastramento dos condomínios interessados em participar do presente projeto. Os resultados esperados envolvem os princípios da sustentabilidade ambiental do entorno analisado, visando à transformação do óleo de cozinha residual coletado em biodiesel e possibilitando uma futura utilização em maquinários do UniBH, reduzindo custos. No âmbito social, foram produzidos materiais de limpeza para doações às Instituições de caridade do entorno e para promoções e distribuição em eventos. Após as ações no âmbito ambiental, espera-se uma mudança de hábitos dos moradores dos condomínios, determinada pela educação ambiental.

No entanto, segundo Lima e Moraes (2009), o crescimento populacional e as inovações tecnológicas influenciam diretamente a geração de resíduos, devido ao aumento do consumo e à caracterização obsoleta dos bens produzidos. Conforme o estudo de Brehm et al. (2011), a geração de resíduos sólidos urbanos no Brasil cresceu cerca de 6,8\% entre 2009 e 2010. Diante disso, o gerenciamento destes resíduos caracteriza-se principalmente pela grande importância ambiental na atualidade.

O óleo vegetal de cozinha é utilizado no preparo de alimentos, conforme apresentado por Brehm et al. (2011) e compõe qualitativa e quantitativamente um dos resíduos urbanos gerados no Brasil. Estima-se que nacionalmente sejam produzidos quatro bilhões de litros de óleo de fritura por ano, sendo metade descartada e a outra metade incorporada no alimento preparado.

No entanto, apenas $5 \%$ do óleo de cozinha descartado são reciclados, não recebendo uma atenção quanto ao seu descarte, que pode afetar os corpos d'água existentes no âmbito geral (SILVEIRA; VIEIRA, 2011).

Ainda de acordo com Silva e Freitas (2011), o problema se agrava ao se considerar a quantidade de água potável disponível para o consumo humano, apenas $0,03 \%$, e também a interligação dos corpos d'água, que é um fator que contribui para a propagação do material poluidor.

Desta forma, o gerenciamento correto e a destinação final deste resíduo, a partir de um projeto de reciclagem, torna-se uma alternativa para solucionar o problema ao considerar o potencial poluidor do óleo de cozinha usado, quando descartado incorretamente, devido a uma legislação obsoleta e a falta de políticas públicas relacionadas ao seu recolhimento. 
Com base nesse contexto, objetiva-se com este trabalho desenvolver um esboço de um projeto para a reciclagem de óleos residuais domésticos, minimizando $o$ descarte inadequado e propondo algumas medidas relacionadas com as questões econômica, social e ambiental.

\section{MATERIAIS E MÉTODOS}

Segundo o IBGE - Instituto Brasileiro de Geografia e Estatística, a cidade de Belo Horizonte/MG conta com aproximadamente 2,5 milhões de habitantes, apresentando uma extensão territorial de $331.400 \mathrm{~km}^{2}$. Sua densidade demográfica é entorno de $7 \mathrm{mil}$ $\mathrm{hab} / \mathrm{km}^{2}$, distribuídos através de nove regiões, da qual faz parte a região oeste, onde se localiza o UniBH.

A região oeste compreende em torno de vinte bairros, dos quais o bairro Buritis foi selecionado para compor o presente estudo.

O referido bairro encontra-se em intenso processo de urbanização e desenvolvimento, sendo um dos principais processos observados a verticalização da região. Tal processo possibilita 0 aumento da concentração populacional no bairro, o que se relaciona diretamente com o aumento do consumo e geração de resíduos sólidos.

\subsection{Gerenciamento do Óleo de Cozinha Residual em Belo Horizonte /MG}

Para o desenvolvimento do trabalho, foi necessária uma breve análise sobre o gerenciamento do óleo de cozinha residual em Belo Horizonte. Seguindo essa metodologia, o referido município atualmente não dispõe de uma regulamentação específica para a destinação dos resíduos urbanos gerados pela sociedade, bem como para o gerenciamento do óleo residual gerado pelos empreendimentos comerciais e/ou domiciliares.
Portanto, o descarte do óleo utilizado deveria ser encaminhado ao aterro sanitário e/ou para reciclagem por profissionais especializados. Entretanto, é válido pontuar que, na maioria das vezes, o óleo de cozinha residual é descartado de maneira inadequada na rede de captação de esgoto, através do despejo em pias e ralos, podendo, assim, contaminar os cursos d'água. Estima-se que um litro de óleo polua aproximadamente vinte mil litros de água, ao se considerar o padrão estabelecido pela resolução CONAMA 357/2006. (RODRIGUES, 2007 apud BREHM et al. 2011).

\subsection{Reciclagem de Óleo de Cozinha Residual}

No início das atividades de reciclagem do óleo residual, foi aplicado um questionário (Figura 1) aos síndicos dos condomínios do entorno do Campus do Centro Universitário de Belo Horizonte, no bairro Buritis, sendo possível o conhecimento das características do edifício residencial e identificação de como era realizado o descarte do óleo residual gerado pelos moradores.

O levantamento possibilitou o cadastramento dos condomínios interessados em participar do projeto e a infraestrutura necessária para o recolhimento do óleo residual para análise e sua transformação em laboratório.

O projeto também previu a instalação de coletores nos condomínios e o recolhimento de certa quantidade de óleo quinzenalmente, para testes em laboratório, sendo essa matéria-prima destinada à produção de biodiesel e uma outra para fabricação de materiais de limpeza, tais como sabão e detergente, e outros, para doação a instituições carentes e/ou eventos promocionais, respectivamente, evidenciando os cuidados sobre o descarte desse insumo no meio ambiente. 
1. Nome e endereço do condomínio:

2. Nome do síndico e contato:

3. Distância do UNIBH Campus Estoril:

4. Número de andares:

5. Número de apartamentos:

6. Número de moradores:

7. Têm problema com caixa de gordura?

( ) Sim. O que fazem?

( ) Não.

8. Medida de logística para o óleo usado:

( ) Fazem recolhimento: Para onde destinam?

( ) Outros: Qual é a destinação final?

9. Podemos realizar o recolhimento do óleo usado gerado pelos moradores, disponibilizando o coletor? ( ) Sim. ( ) Não.

10. Qual o melhor período para o recolhimento?
( ) Manhã
( ) Tarde
( ) Noite

Agradecemos a participação;

Equipe do projeto

Figura 1: Levantamento das condições de descarte do óleo de cozinha residual em condomínios no entorno do campus UNIBH- Questionário sócio ambiental

\subsection{Desenvolvimento do Projeto}

O desenvolvimento do projeto foi baseado na experiência de alguns autores, como Morás e Silva (2009). No entanto, buscaram-se novas rotas para evidenciar o melhor aproveitamento do óleo coletado. Neste contexto, o estudo foi dividido em quatro eixos:

Eixo 1. Levantamento da situação de coleta do óleo, orientação ambiental para os condôminos do entorno da UniBH. 
Eixo 2. Estudos em laboratório visando à produção de sabões com baixa alcalinidade para doação a instituições carentes da grande Belo Horizonte.

Eixo 3. Produção de biodiesel para uso em maquinários institucionais. Desenvolvimento de um catalisador para o processo de hidrogenólise do glicerol produzido.

Eixo 4. Estudos avançados para reação de hidrogenólise do glicerol na produção de produtos com maior valor agregado.
No entanto, neste artigo, apresentam-se os resultados das duas primeiras etapas. Sendo que as etapas seguintes se encontram em desenvolvimento.

\section{Resultados e discussões}

Os resultados esperados envolveram os princípios da sustentabilidade, com o envolvimento das áreas ambiental, econômica, social e uma melhor formação do egresso em Engenharia, como demonstrado através da Figura 2.

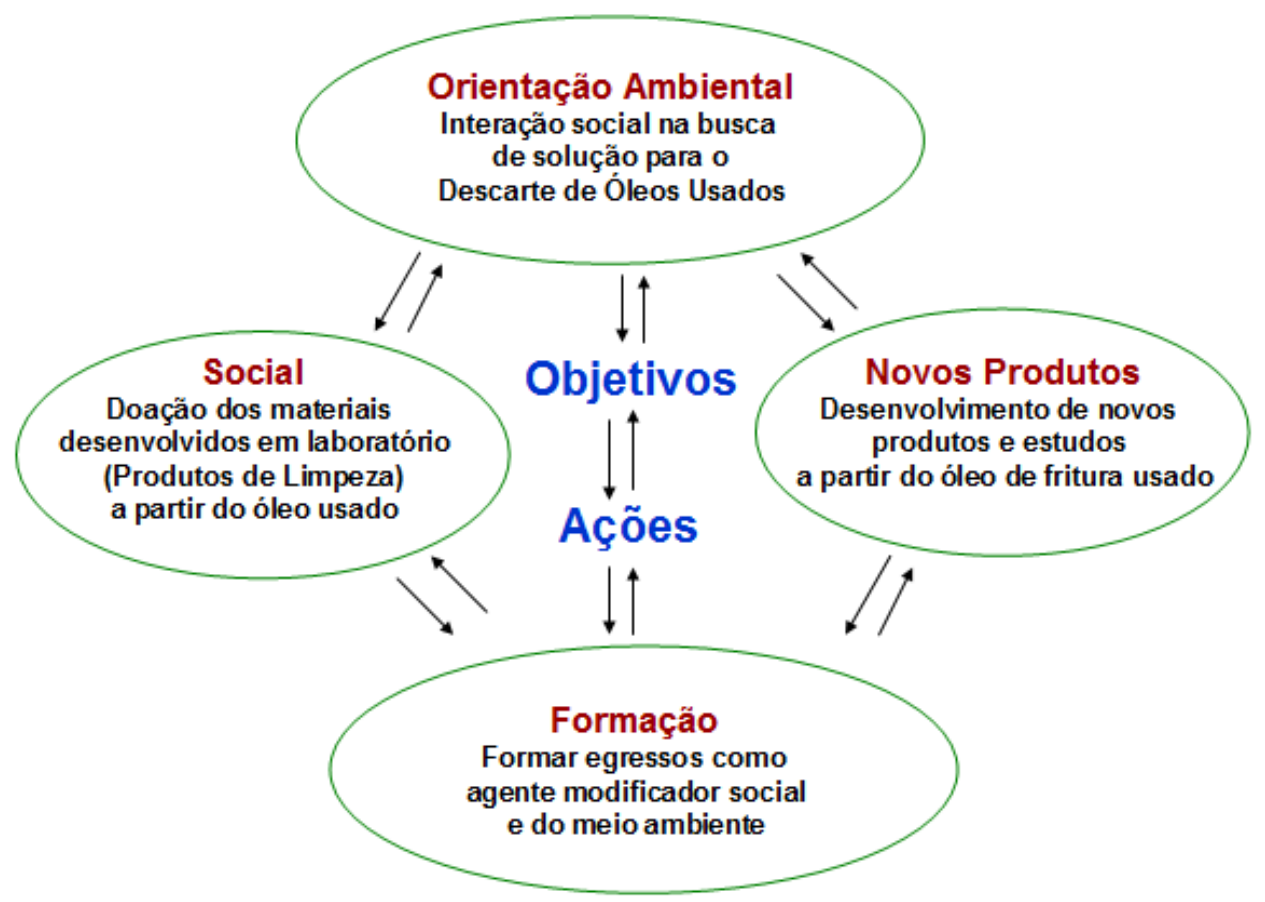

Figura 2: Aspectos trabalhados no projeto

Através da aplicação e análise do questionário sócioambiental (Figura 1) foi possível conhecer e estabelecer procedimentos para a coleta, transporte, processamento do óleo e as orientações ambientais que seriam concedidas à comunidade pelos discentes (figuras 3 e 4).

As ações ocorreram no entorno do Campus UNIBH e envolveram cinquenta condomínios com distância aproximada de $2 \mathrm{~km}$ de sua entrada principal. No entanto, apenas cinco condomínios visitados aderiram ao projeto, ou seja, $10 \%$ do total. Os possíveis motivos da baixa adesão podem estar relacionados com a falta de conhecimento do potencial poluidor do óleo de fritura residual, a não utilização desse produto no preparo de alimentos e/ou interesse da participação na pesquisa. 


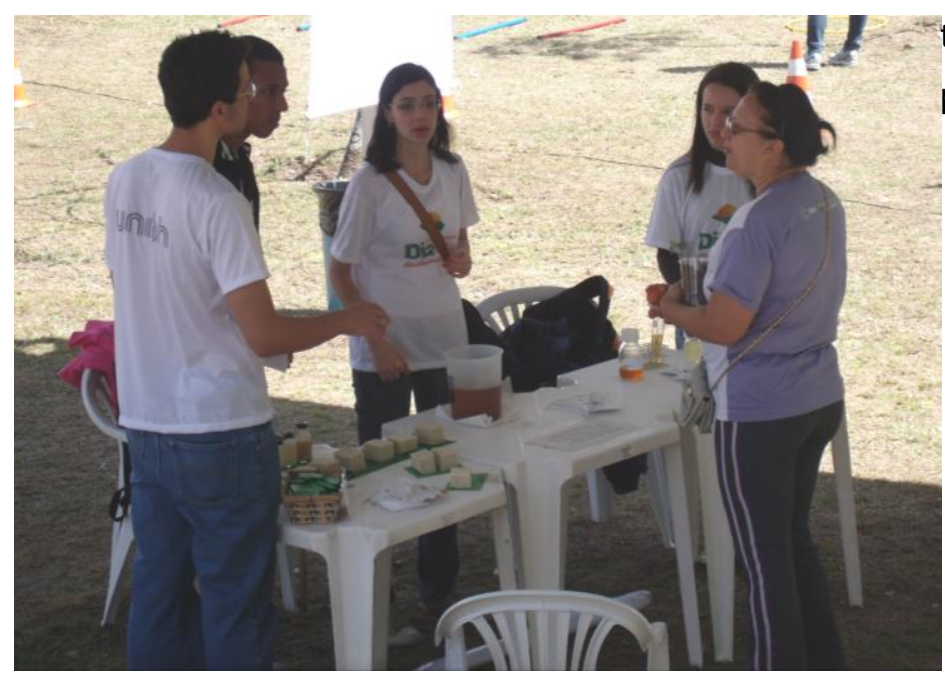

Figura 3. Orientações concedidas à comunidade. Evento: Dia de Responsabilidade Social/2012 (Discentes da esquerda para direita: Diego Vinaud, Victor Campos, Luciana Ribeiro, Julianah Campos)

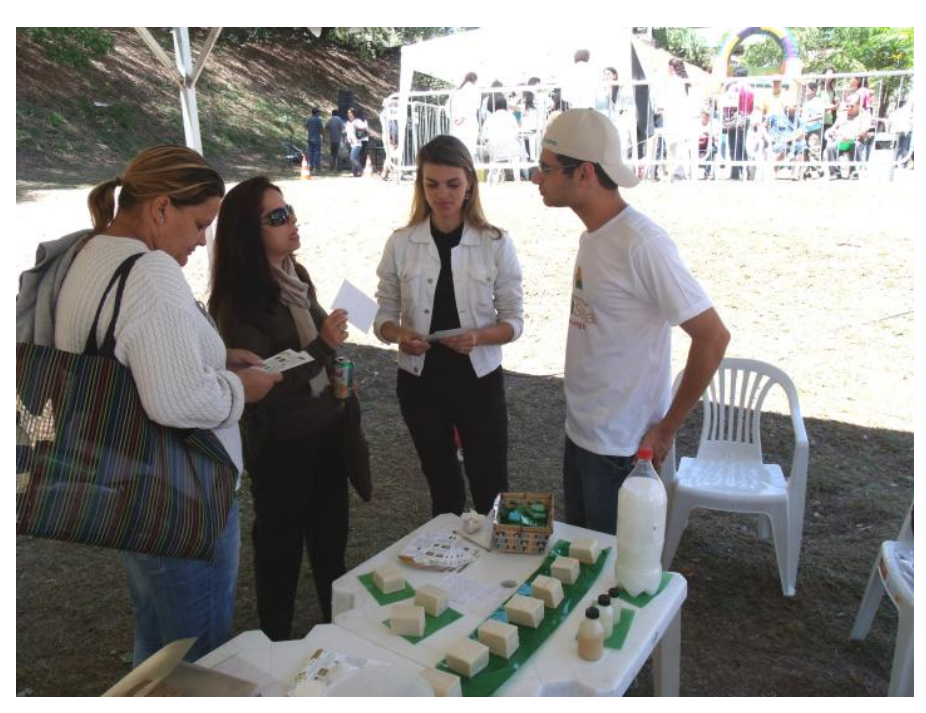

Figura 4. Orientações concedidas à comunidade. Evento: Dia de Responsabilidade Social/2013. (Discentes da direita para esquerda: Mateus Xavier e Petrina Santos - Líderes do grupo)

Verificadas as necessidades da coleta e transformação do óleo, foi estabelecido o UNIBH como ponto de coleta do óleo, sendo uma parte do óleo estudada em laboratório e a outra encaminhada para a empresa Recóleo, que atua no recolhimento do óleo na cidade de Belo Horizonte-MG. Os estudos possibilitaram a obtenção de sabões (detergentes) e biodiesel (figuras 3,4 e 5 ), sendo os sabões doados às instituições carentes cadastradas no projeto e também distribuídos através de promoções em participações de eventos.

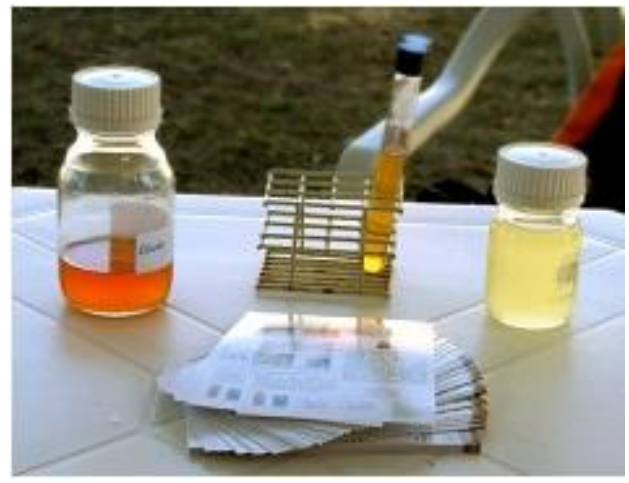

Figura 5. Biodiesel (amarelo dourado) obtido a partir de óleo de cozinha residual (coloração laranja à

marrom-laranjada) e panfletos de divulgação.

Portanto, o estudo possibilitou o emprego dos princípios de sustentabilidade, envolvendo a área ambiental, econômica e social. Ressalta-se também na verificação que o estado de Minas Gerais ainda não tem uma legislação específica para a destinação de resíduos sólidos, bem como para o gerenciamento do óleo de cozinha residual. Devido ao fato, houve a necessidade de se buscar alternativas para transformar o óleo coletado em produtos de detergência (sabões) e biodiesel. Como uma alternativa secundária, ainda em estudo, a transformação do glicerol obtido do processo de transesterificação do óleo na obtenção do biodiesel ocorrerá através da presença do catalisador $\mathrm{Ru} / \mathrm{Nb}-\mathrm{Al}$ MCM-41, preparado em laboratório, para produção de 1,2 propanodiol.

\section{AGRADECIMENTOS}

Ao apoio concedido pela FAPEMIG (Proc.: APQ00432-11-Edital Universal), Núcleo Acadêmico do UniBH, pelas bolsas concedidas, e aos discentes que se envolveram direta ou indiretamente no projeto no período de 2012 até o primeiro semestre de 2014, dos cursos de Eng. Química e Eng. Ambiental do UniBH, sendo os nomes listados na sequência: 
Adriano Pereira Lacôrte

Alexandre Montenegro Nascimento Vilarinhos

Alisson Brandão

Ariane Santos - Líder de Grupo de Pesquisa

Ana Carolina Gonçalves

Bárbara Sanches

Camila Nayara

Danielle Artemis Quirino Nelson

Diego Saldanha Vinaud

Danielle Noqueira

Guilherme Mendes - Líder de Grupo de Pesquisa

Hélio Junior

Julianah Teresa Oliveira Campos

Kelly Tinoco de Souza
Ludmila Sara da Costa Pereira

Luciana Sampaio Ribeiro

Mariana Cristina de Almeida Alípio

Mariany Vieira Furtado

Mateus Santos Xavier - Líder de Grupo de Pesquisa

Nathália Soares Barbosa

Natália Cristina Marcelino Gonçalves

Paula Andrade da Conha

Petrina Teixeira Santos - Líder de Grupo de Pesquisa

Raphaela Nayara de Sena Pinto

Ricardo Faria

Valéria Dornelas de Oliveira

Victor Barbosa Campos - Líder de Grupo de Pesquisa.

\section{REFERÊNCIAS}

BREHM, F. A. et al. Reciclagem do óleo de cozinha usado na fabricação de sabão para a qualificação de um grupo de economia solidária. Anais. $26^{\circ}$ CONGRESSO BRASILEIRO DE ENGENHARIA SANITÁRIA E AMBIENTAL. 2011.

CHEN, L. Y., JAENICKE, S., CHUAH, G. K., Thermal and Hydrothermal Stabity of Framework-Substituted MCM-41 Mesoporous Materials. Microporous

Materials. 12, p. 323, 1997.

IBGE - INSTITUTO BRASILEIRO DE GEOGRAGIA E ESTATÍSTICA. Cidade de Belo Horizonte/MG.

Disponível em:

$<$ http://www.ibge.gov.br/cidadesat/link.php?codmun=3 $\underline{10620}>$ Acesso em: 14 set. 2014.

LIMA, D. O. L.; MORAES, L. R. S. Coleta seletiva de óleo vegetal residual em restaurantes de Salvador/BA: Um estudo de caso em estabelecimentos filiados à ABRASEL. Anais. $25^{\circ}$ CONGRESSO BRASILEIRO DE ENGENHARIA SANITÁRIA E AMBIENTAL. 2009.

MELO, R. Síntese e Propriedades da Peneira Molecular Mesoporosa MCM-41. Tese de Doutorado (Engenharia Química) Universidade Federal de São Carlos - UFSCar-SP. São Carlos, 2000.
MICHAEL M. J., Hidrogenólise seletiva do glicerol em catalisadores de rutênio suportado em nióbio, sílica e alumina. Dissertação de Mestrado. Universidade Estadual de Campinas - UNICAMP, Campinas/SP, 2010.

MORÁS, P. B.; SILVA, J. D. Programa de reciclagem do óleo doméstico em Mandiritura/PR: Estudo de caso. Anais. $25^{\circ}$ CONGRESSO BRASILEIRO DE ENGENHARIA SANITÁRIA E AMBIENTAL. 2009.

SILVEIRA, D. A.; VIEIRA, G. E. G. Processo de filtração a vácuo de óleo residual utilizado em fritura visando à produção de biodiesel. Anais. $26^{\circ}$ CONGRESSO BRASILEIRO DE ENGENHARIA SANITÁRIA E AMBIENTAL. 2011.

SILVA, B. D. S.; FREITAS, T. A. V. Reutilização do óleo de cozinha. Anais. $26^{\circ}$ CONGRESSO BRASILEIRO DE ENGENHARIA SANITÁRIA E AMBIENTAL. 2011. 